\title{
Wired: Computer Networks in the English Classroom
}

\author{
Joyce Kinkead
}

Mail is seductive. I'm talking about the power that draws us inextricably to our mailboxes each evening to pore over letters, sweepstakes invitations, and yuppie catalogs. Imagine what happens when that power is integrated into a "hot" medium-the computer. The result? Electronic mail, casually known as e-mail.

If your school has computers, most likely you can tap into that resource to establish a network that allows writers to communicate with one another via computer links. Some computer systems have networks built in automatically-such as a mainframe or a UNIX operating system (standard on AT\& T equipment); other systems have networking capabilities so that given the right hardware and software, computers can "talk" to each other. E-mail is standard on the more powerful, larger systems. In addition, mainframes often hook into BITNET, an international e-mail system; for example, because my school has BITNET access, when I log onto my computer, the return addresses include Sweden and Canada as well as Kansas City and Ithaca.

I am not a "tekkie" though, and the purpose of this article is not to describe hardware and software. As English teachers, our role is to ask why we want computers available to our students, and what we will do with them. Frankly, computers mean big bucks, and if we don't have sound pedagogical reasons for them, then they are worthless. Computers purchased so that students may do grammar worksheets on screen fit the worthless category; however, computers used so students may write and rewrite with greater ease have value. Most computer/writing rooms are designed with word processing in mind-often including spell and style checkers. As another way to make those computer dollars pay off, networking offers a collaborative model for writing and learning that word processing alone often does not.

Pedagogically, our goal is for students to become better writers by writing purposeful, meaningful prose. In short, real writing for real audiences. Electronic mail helps serve just that function. Here are possibilities for writing projects using e-mail.

\section{Peer Response}

In addition to peer response groups within the class, students "mail" essays to one another and by return mail send written critiques to the authors. The same rules for oral response groups apply: (1) students focus on what the author has done well, complimenting good details, examples, organization, or word choice; (2) responders offer suggestions for improving, noting places in the text that are hard to understand. Students who respond to texts via mail have reported that they really appreciate the extra time to "get in touch" with the writing, and they don't feel pressured. They also note that they have to respond; in contrast, "shy" talkers may get lost in group response.

\section{Mentor Projects}

The mentor model can cut both ways for students. First, there are mentors for them. This could be seniors for a sophomore class. Or, AP students find corresponding with college students insightful. Responding to each other's writing is one way of tapping the expertise of mentors, but there are other information exchanges. For example, the 
students in a young adult literature course at a university eagerly await letters from real teenagers (translation: their future students) to find out the high-school students' perceptions of reading and writing. Over the term, the college and highschool students read the same texts and share their responses. In one writing assignment based on Hal Borland's When the Legends Die, a highschool student wrote her own "morning song":

Oh Lord as I lay down to sleep,

I pray that thou will never make me wake.

Mornings are only for grumps

And coffee bums

And if you let me sleep,

I promise to be neither one.

Ten minutes more

$\mathrm{OK}$, at least five.

OK, I'm up,

but not alive.

Another assignment coming out of the same novel focused on a review of the film version as the high-school students advised "thumbs up or

\section{The flip side of the coin is that students can be mentors to other students also.}

thumbs down" to the college students. One reviewer, calling herself a "smaller version of Roger Ebert," wrote,

Don't waste your money on this one; the film leaves out a lot of good stuff, like the bear hunt at the end and anything about Tom's parents at the beginning. It even has Tom friendly with Red, which is not true to his character. Overall, I'd say the book is round while the movie is flat.

The flip side of the coin is that students can be mentors to other students also. A recent collaborative project in our community involved highschool students pairing with elementary students to write and illustrate children's books for the library. The authors (older students) interview the illustrators (younger students) via e-mail, finding out what kind of stories the children enjoy and brainstorming for plot and character. Such a project goes beyond the classroom walls and engages students at both levels in real writing.

\section{Writer's Notebook}

Because we often do not have time during a class discussion to hear everyone's opinions on a literary text, it's helpful to read responses from students via e-mail. Often, I get a better picture of a student's understanding of a text from a paragraph than I do from class discussion, which is necessarily abbreviated. Moreover, I can give students individual feedback on a mail message without taking up class discussion time and without taking the emphasis away from a student-centered class. Consequently, a teacher and student may have a dialogue via e-mail. One student who really enjoyed Madeleine L'Engle's A Wrinkle in Time investigated further and wrote via e-mail that "L'Engle received many rejection slips for her novel ... the reason often given that the book dealt too much with the problem of evil. The book eventually was published and won the 1963 Newbery Medal." Email provides an outlet for sharing knowledge. This student takes the responsibility of learning on her own shoulders and makes the teacher a colearner.

This dialogue also allows for metacognitive activities in which the students reflect on their thinking. If I ask them to reflect on how response groups work, I am asking them to do a metacognitive activity. Here is Afton's response to that question:

I gained a great deal from talking with Laura and Karen about my paper. They didn't have too many comments about mechanics, but continuity and flow were something else. Everywhere I had been uncertain, they were more uncertain.

Besides asking students to analyze group dynamics, I may query them about how they reached an interpretation for "Ozymandias" or how various brainstorming strategies worked for them in planning to write. All of these allow me to see how much the student is learning - another way to be sure my evaluation of their work is on target and to find out who needs extra help.

\section{Ask Abigail}

Advice columns are not news-unless they are written electronically. Students may request help with writing problems from a designated "tutor"-an anonymous guide who provides advice on literature, test-taking, writing, or grammar. Requests from students may vary from "How do I punctuate dialogue?" to "What is plagiarism?" Already some schools have such reference sources in their libraries for ready help. 


\section{Bulletin Boards}

Some systems offer a bulletin board service so that all users receive the latest news whenever they log on. The same thing can be accomplished on email by establishing distribution lists; consequently, e-mail not only allows one person to write to one other person but makes it possible for one message written by one person to be delivered to twenty-five people -or three hundred. That communication design lets teachers write to entire classes at once, offering additional information on authors, follow-ups to class discussion, or helpful tips for writing the term paper.

\section{Writing across the Curriculum}

The projects above were designed with the English classroom in mind, but they are not restricted to that audience. Students in various content areas-art, vo-tech, music, history-benefit by writing in these areas and can help/inform students in other areas by offering their expertise.

\section{Teachers can do most of these collaborative projects without any hardware at all. It's just easier with computers.}

The peer response model fits easily into this scenario, too.

Although these projects focus on the student, teachers profit by being "wired," too. Normally carrying the burden of incorporating WAC, English teachers can practice what they preach by informing content area teachers about the advan- tages of integrating writing, following up those tips with e-mail conferences. Another audience for the English teacher includes administrators. Imagine a school where memos are not delivered on paper but are sent electronically: "Today's Announcements" arrive on screen. Or, teachers send supply requests without leaving the classroom.

These ideas do not require costly hardware and software; in fact, teachers can do most of these collaborative projects without any hardware at all. It's just easier with computers.

Two of the barriers in the classroom-time and distance-are being removed as a result of electronic communication links. Distance education is a new phrase in the profession as telecommunications reach out to audiences previously disadvantaged by miles. For a teacher, this means sitting down at a home workstation and responding to a ninth grader's question on homework, reading an AP student's excited response to Anna Karenina, or writing a request for more computer stations to the principal. The computer mail facility is as seductive for students as it is for teachers. Although I thought I might resent students' intruding into my own time after school hours, I find instead that I enjoy our correspondencesthat I get to know students better and they know me better, too, a benefit that transfers to our classroom. I'm championing this opportunity for students to write and read in yet a different wayelectronic text. I recommend getting "wired" for writing.

Utah State University Logan, Utah 84322 